\title{
Research of Dust Transport Rule of Large Difference Chute Based on FLUENT
}

\author{
Lan $\mathrm{JIA}^{{ }^{1,2, a}}$, Dong-Xing WANG ${ }^{1, \mathrm{~b}}$, Chang-Wu YU ${ }^{1, \mathrm{c}}$ and Bing LIANG ${ }^{2, \mathrm{~d}}$ \\ ${ }^{1}$ School of Chemistry and Environmental Engineering, Liaoning University of Technology, Jinzhou \\ 121001, Liaoning Province, China \\ ${ }^{2}$ School of Mechanics and Engineering, Liaoning Technical University, Fuxin 123000, Liaoning \\ Province, China \\ ajialan.lan@163.com, b1037041986@qq.com, c 25223780@qq.com, dIbwqx@163.com
}

Keywords: Large difference chute, numerical simulation, dust, migration law, FLUENT.

\begin{abstract}
To achieve the green backfill of an abandoned open pit mine with a large difference chute process system, Fushun West open pit mine is used as the research subject. Based on the theory of gas-solid two-phase flow and the characteristics of large difference chutes, FLUENT numerical simulation software was used to carry out the numerical simulation of the trajectories of dust particles in the chute. The influence factors of the dust movement and the relationship between the factors were explored. The numerical simulation results showed that, the greater the material flow rate, the more serious the resulting dust pollution. The larger the chute angle, the greater the acceleration of the backfill material, and the greater the dust concentration. Therefore, as far as possible, to control the flow rate of the material, a suitable chute angle and U-shaped section of the chute should be selected to control powder or moisture content; these are effective measures by which to reduce dust precipitation.

An applied in open pit mine backfill chute, the elevation difference can reach at least hundreds of meters. The large elevation difference chute process system transports rock; in this process, it produce large amounts of dust pollution, leads to the deterioration of the production environment, and causes a variety of occupational diseases [1]. Open pit mine large difference chutes have a certain degree of particularity [2]. First, the controlled space of the large difference chute and the mine fully mechanized coal mining face and tape transport system are different. The chute itself is a semi-enclosed space structure, and the chute is exposed to the pit. Dust movement in the space was relatively large, and is more greatly impacted by external environmental factors. Second, the large difference of the chute transported traffic up to several tens of cubic meters per second. Third, the material flows fast and the impact is considerable.

Abroad, the chute transport dust movement law research has focused on the chute transfer point, where the mine fully mechanized coal mining face, roadway belt conveyor, transfer point of the dust, and the big difference between the chute dusts movements are all areas of gas-solid two-phase flow. However, the mechanism and regularity of dust generation and migration in large differential chutes were not comprehensive and thorough, and there is a lack of numerical simulation model construction [3-6]. There are a variety of factors that affect the movement of dust [7]: the Fushun West Open-pit Mine was the research background, and the factors affecting the dust movement of the large differential chute system and the relationship between the influencing factors were explored; this was in an attempt to clarify the mechanism and the movement law of dust in the process of large difference chute system transportation. This has a positive effect on the environmental management of dozens of abandoned open pit mines, and open pit mines in China, which promotes the development of chute technology.
\end{abstract}

\section{Mathematical Model of Gas-solid Two-phase Flow in Dust Movement}

The numerical simulation of dust migration in the chute was carried out using FLUENT computational fluid dynamics software. The calculation ignored other effects, and only considered the effect of the gas flow field on the role of particles [8]. 


\section{Mathematical Model of Airflow Field}

The velocity of the air flow in the chute is related to the ambient wind speed and the material flow rate in the pit. Therefore, the representative wind speed was chosen as the research subject, and velocities of $2,3,4,6,12$, and $24 \mathrm{~m} / \mathrm{s}$ were investigated.

The calculated Reynolds numbers and turbulence intensities of the wind flow are shown in Table 1 for various wind speed conditions [9].

Table 1 Reynolds and turbulence intensity at different wind velocities

\begin{tabular}{ccc}
\hline $\begin{array}{c}\text { Wind speed } \\
(\mathrm{m} / \mathrm{s})\end{array}$ & $\begin{array}{c}\text { Reynolds } \\
\text { number }\end{array}$ & $\begin{array}{c}\text { Turbulence } \\
\text { intensity (\%) }\end{array}$ \\
\hline 2.0 & 442243.21 & 3.15 \\
3.0 & 663364.82 & 3.00 \\
4.0 & 552804.01 & 2.89 \\
6.0 & 1326729.63 & 2.75 \\
12.0 & 2653459.26 & 2.68 \\
24.0 & 5306918.52 & 2.56 \\
\hline
\end{tabular}

\section{Particle Phase Mathematical Model}

The Euler-Lagrangian method was used in this study. The fluid phase was regarded as the continuous phase, and the N-S equation was solved. The discrete phase was obtained by calculating the motion of a large number of particles in the flow field. The calculation of the particle motion in the flow field was based on the following assumptions [10]:

(1)All rock particles in the flow field were regarded as spheres with the same density.

(2)The density of the rock particles was much greater than the density of the gas.

(3)There was no strong heat source inside the flow field, and the fluid inside the chute, and the air temperature did not change much, ignoring the heat exchange; this represents a constant isothermal field.

\section{Geometric Model Establishment and Meshing}

A geometrical model of length $200 \mathrm{~m} \times$ width $4 \mathrm{~m} \times 5 \mathrm{~m}$ height was established. The continuous phase was air and the discrete phase was rock dust particles with a density of $2300 \mathrm{~kg} / \mathrm{m}^{3}$. According to the dust generation mechanism, it was assumed that the dust particles were laid on the bottom of the chute and the shear air flow entered from the bottom of the chute (in a direction opposite to that of the flow) [11]. The chute grid division are shown in Fig. 1, respectively.

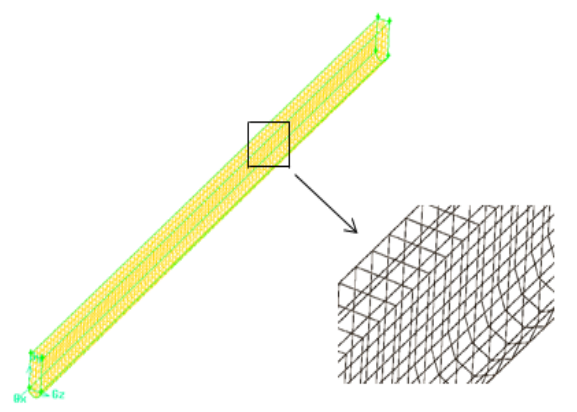

Fig. 1 Mesh of roadway model

\section{Numerical Simulation Parameters and Setting of Boundary Conditions}

The groove was set to the 'velocity-inlet' boundary condition; the exit to the 'outflow' boundary condition; and the wall of the chute to the reflection 'reflect' boundary condition. The elastic 
recovery coefficient was set, and the exit was set to the 'escape' boundary condition.

According to the mathematical model of the gas flow field, the numerical simulation parameters were set as shown in Table 2 [9].

\section{Numerical Simulation Results and Analysis}

\section{Effect of Material Flow Velocity on Dust Particle Transport}

The induced airflow from the bottom of the chute to the opposite direction (direction and logistics direction) was selected from the representative induced wind speeds in the study, namely $5,10,15$, and $20 \mathrm{~m} / \mathrm{s}$.

Table 2 Simulation parameter settings

\begin{tabular}{|c|c|c|c|c|c|}
\hline Project & Name & Parameter setting & Project & Name & Parameter setting \\
\hline \multirow{4}{*}{$\begin{array}{c}\text { Calculate } \\
\text { model } \\
\text { settings }\end{array}$} & Solver & $\begin{array}{c}\text { Pressure base } \\
\text { solution }\end{array}$ & & Type of jet source & Face dust source \\
\hline & Turbulence model & $\begin{array}{c}\text { k- } \varepsilon \text { two-equation } \\
\text { model }\end{array}$ & Dust & Particle flow number & 17.3 \\
\hline & Energy equation & Shut down & source & Material & Low volatile coal \\
\hline & Discrete phase model & Turn on & parameter & Particle size distribution & R-R distribution \\
\hline \multirow{9}{*}{$\begin{array}{c}\text { Boundary } \\
\text { condition } \\
\text { setting }\end{array}$} & Entry boundary type & Speed entrance & setting & Maximum particle size /m & $1000 \times 10-6$ \\
\hline & Entrance speed /(m s-1) & 2 & & Minimum particle size /m & $1.0 \times 10-6$ \\
\hline & Hydraulic diameter /m & 4.44 & & $\begin{array}{l}\text { Initial velocity of the dust } \\
\qquad /\left(\mathrm{m}^{\mathrm{s}} \mathrm{s}-1\right)\end{array}$ & 2.0 \\
\hline & Turbulence intensity /\% & 3.15 & Discrete & Calculate the number of steps & 400 \\
\hline & Export boundary type & Free outflow & phase & Time Step & 1 \\
\hline & DMP boundary & Escape & $\begin{array}{c}\text { parameter } \\
\text { setting }\end{array}$ & Resistance characteristics & Spherical particles \\
\hline & Cut the border & No slip & Solve & Pressure-speed coupling & SIMPLEC algorithm \\
\hline & Wall roughness /m & 1.0 & parameter & Discrete format & Second-order upwind \\
\hline & Wall roughness constant & 0.5 & settings & Convergence criteria & $10-6$ \\
\hline
\end{tabular}

In the chute, a dust particle with a particle size ranging from 1 to $1000 \mu \mathrm{m}$ (particle size obeys Poisson distribution; ten of particle size distributions; average particle size of $10 \mu \mathrm{m}$ ) was placed on the bottom of the chute, and the calculation volume was $200 \times 4 \times 5 \mathrm{~m}^{3}$. The simulation results of the dust particles' trajectories are shown in Figure 2.

The dust particles were lifted at a rate of $5 \mathrm{~m} / \mathrm{s}$ under the induced airflow; dust particles at a speed of more than $10 \mathrm{~m} / \mathrm{s}$ induced airflow and raised the dust particles the most. At a flow rate of $20 \mathrm{~m} / \mathrm{s}$, almost all of the small particles were raised, resulting in the maximum concentration of dust in the chute. From these simulation results, we can see that the greater the velocity of the material, the greater the induced airflow rate [13], The greater the buoyancy imparted to the dust particles, the faster the collision between the particles and the more intense the Brownian movement, resulting in the dust particles from the original trajectory escaping to the atmosphere more easily. The greater the amount of dust generated, the more serious the pollution [12]. 


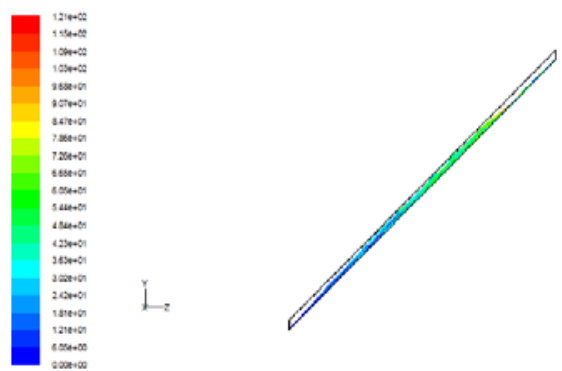

(a)Dust particle trajectory at $5 \mathrm{~m} / \mathrm{s}$
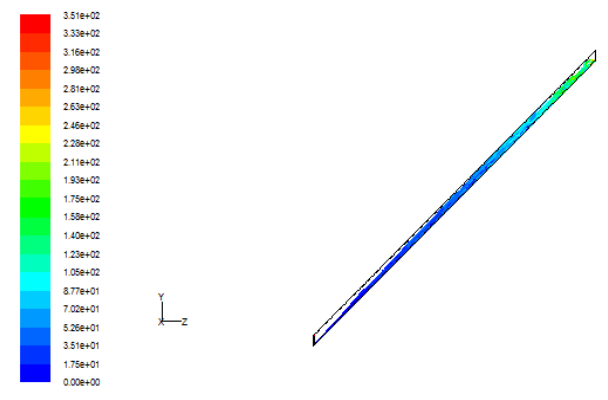

(b)Dust particle trajectory at $10 \mathrm{~m} / \mathrm{s}$
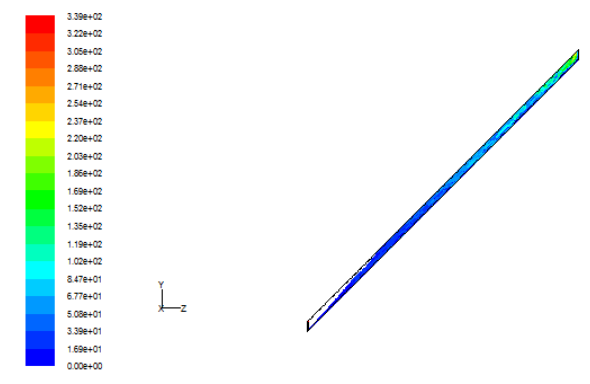

(c)Dust particle trajectory at $15 \mathrm{~m} / \mathrm{s}$
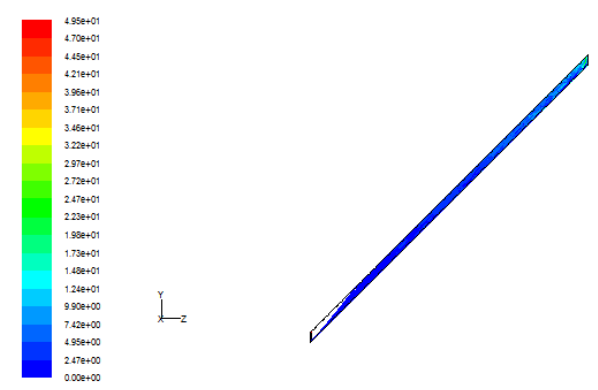

(d)Dust particle trajectory at $20 \mathrm{~m} / \mathrm{s}$

Fig. 2 Dust particle movement trajectories of different induced airflow velocities

\section{Effect of Particle Size on Dust Particle Transport}

The induced airflow velocity in the chute was $25 \mathrm{~m} / \mathrm{s}$. Particles with particle diameters of 1, 10, 100, and $1000 \mu \mathrm{m}$ were placed on the bottom of the chute model. The calculation field was $200 \times 4 \times 5 \mathrm{~m}^{3}$. The simulated dust trajectory results are shown in Fig 3.

It can be seen from the simulation results in Fig. 3 that the particles with diameters of 1 and 10 $\mu \mathrm{m}$ placed on the bottom of the chute were basically blown up by the air flow, and the dust concentration in the chute is large. Particles with a particle size of 50 and $100 \mu \mathrm{m}$ were partially blown up by the wind and the dust concentration was small. Particle sizes greater than $100 \mu \mathrm{m}$ were 
not able to fly up the chute, resulting in no basic particles in the dust trajectory. The results show that when the particle size increased, the force of the shear gas flow to the particles was not sufficient to overcome their own gravity, and could not fly up. Therefore, the dust particles produced during the chute transport mainly had particle diameters between 1 and $100 \mu \mathrm{m}$.

According to the Fushun West open pit mine backfill material basic properties and particle size distribution [2], the mass fraction of the backfill material was $0.5-4 \%$, the average particle size was $500 \mathrm{~mm}$, the particle size was less than $20 \mathrm{~mm}$, the particle size was less than $100 \mu \mathrm{m}$, and the particle fraction was $0.563 \%$. Thus, the amount of dust generation can be estimated based on the numerical simulation results.
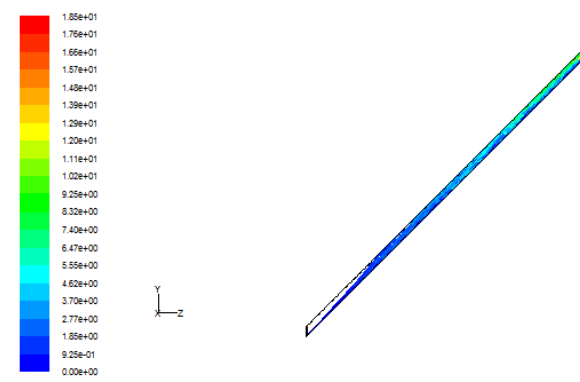

(a)Particle trajectories for a particle size of $1 \mu \mathrm{m}$
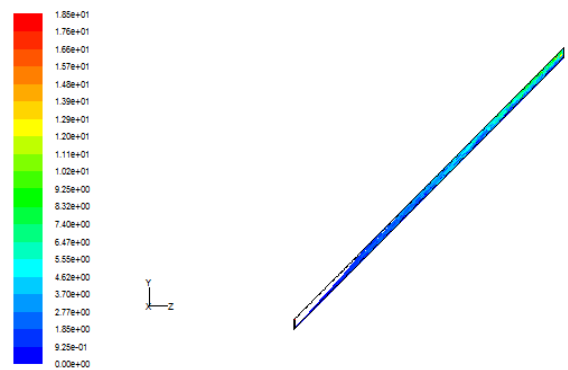

(b)Particle trajectories for a particle size of $10 \mu \mathrm{m}$
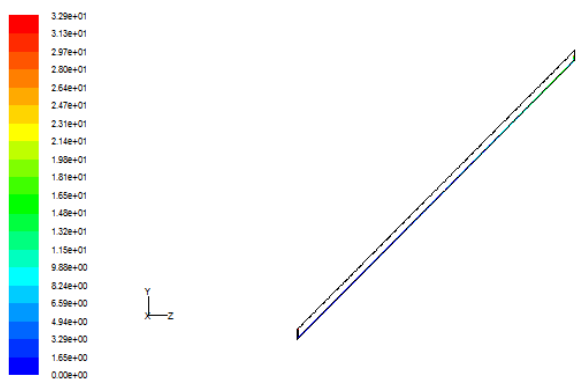

(c)Particle trajectories for a particle size of $100 \mu \mathrm{m}$
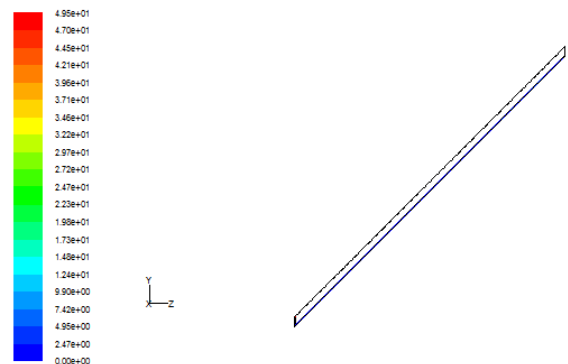

(d)Particle trajectories for a particle size of $1000 \mu \mathrm{m}$

Fig. 3 Dust particle movement trajectories of different size particles 


\section{Effect of Slip Angle on Dust Particle Transport}

Inclination was the main parameter of the design of the large difference chute. The appropriate chute angle was chosen to not only ensure the normal transport chute to meet the flow and speed requirements, but also to ensure the safety of the chute and to ensure environmental protection. For a single angle chute, the chute was, in theory, determined by the coefficient of friction between the material and the chute wall. However, the inclination of the chute had a certain influence on the migration and diffusion of dust particles. The chute angle was set to33 $, 36^{\circ}, 39^{\circ}$ and $42^{\circ}$, respectively, for simulations based on the following assumptions: the chute was laid with a particle size ranging from 1 to $1000 \mu \mathrm{m}$, the calculated field was $200 \times 4 \times 10 \mathrm{~m}^{3}$, and the initial velocity of the material was $2 \mathrm{~m} / \mathrm{s}$. The simulated dust trajectory is shown in Fig 4.

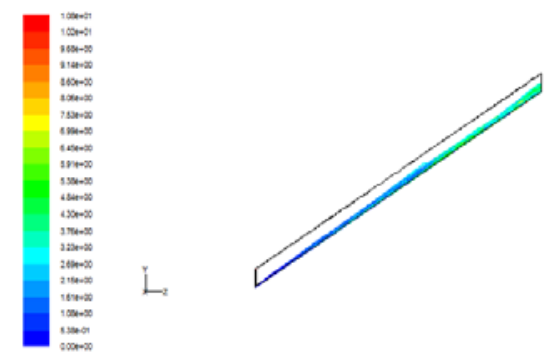

(a)Trajectory of dust particles at an angle of $35^{\circ}$

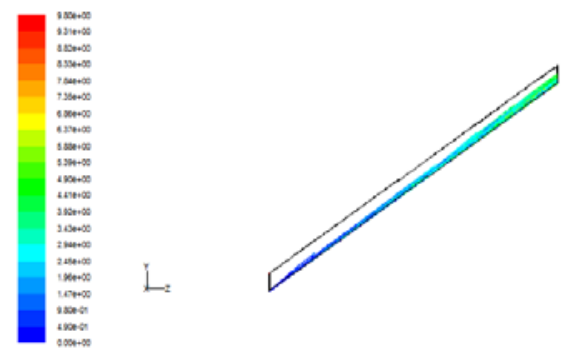

(b)Trajectory of dust particles at an angle of $36^{\circ}$
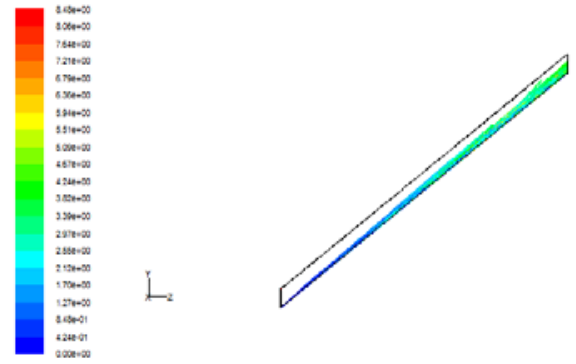

(c)Trajectory of dust particles at an angle of $39^{\circ}$
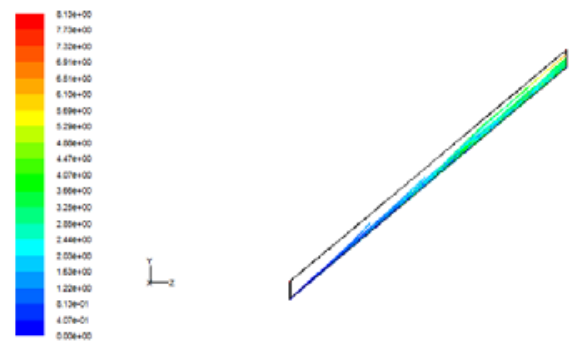

(d)Trajectory of dust particles at an angle of $42^{\circ}$

Fig. 4 Dust particle movement trajectories of different chute inclinations 
As shown in the simulation results in Fig 4, the inclination of the chute had a certain influence on the escape of dust particles in the chute. As the chute angle increased from $30^{\circ}$ to $42^{\circ}$, the overall concentration of dust in the chute was increased gradually. The acceleration of the material in the chute increased, likely as a result of the increased chute angle. The greater the velocity of the material, the greater the induced airflow rate, and the greater the amount of dust rose. From a chute transport efficiency points of view, the greater the tilt, the better. However, from the perspective of safety and environmental protection, the smaller the tilt angle, the better. Therefore, to ensure the normal transport of materials, a reasonable chute angle must be chosen.

\section{Conclusions}

(1)The velocity of the material was the main factor affecting the dust. The greater the material flow rate, the greater the amount of dust produced. For material flow rates greater than $10 \mathrm{~m} / \mathrm{s}$, the small particles of dust were basically raised. Minimizing the flow rate of the material can reduce dust generation.

(2)The majority of the dust particles had a particle size of $100 \mu \mathrm{m}$ or less. Particles with particle sizes greater than $100 \mu \mathrm{m}$ were not easily precipitated. Controlling the powder content of the material can effectively reduce the dust concentration.

(3)The amount of dust generated and chute inclination also had a direct relationship; the greater the chute, the greater the amount of dust produced by the chute. Thus, selecting the right chute can reduce dust pollution.

\section{References}

[1]Song Ziling. Geology Information System setting up and applying in Mimin[C]. The Proceedings of the China Association For Science and Technology. Science Press Beijing/New York, 2004.

[2]Jia Lan. Study on the Key Technology of Backfill Fushun West Open Pit [D]. Liaoning university of engineering technology, 2013.

[3]Zhou Gang,Cheng Weimin,Chen Lianjun, et al. Numerical simulation and its application of dust concentration spatial distribution regularities in fully-mechanized caving face [J]. Coal journal, 2010, 35 (12) : 2094-2099.

[4]Cheng Weimin, Nie Wen, Yao Yujing, et al. Numerical simulation on the flow field of swirling flow air curtain aspiration control dust in fully mechanized workface. [J]. Journal of coal, 2011, 36 (8) : 1342-1348.

[5]A.Katterfeld,T.D.C.A.Wheeler.Simulation Based Dust Prediction of Transfer Chutes. Bulk Solids Handling . 2010

[6]Donohue,T.J,Roberts,AlanW,Wheeler,CraigA,McBride,William.Computer Simulations as a Tool for Investigating Dust Generation in Bulk Solids Handling Operations. Particle \& Particle Systems Characterization . 2009

[7]LI Xiaochuan, Wang Qili, Liu Qi, et al. Influence factors for induced airflow of bulk materials in chute transfer station [J], science and engineering of powder metallurgy materials. 2015.20 (5) : 683-686.

[8]Yu Yong editor. FLUENT entry and advanced tutorial [M]. Beijing Institute of Technology Press, 2008.09.

[9]Zhou Yunlong,Hong Wenpeng,Sun Bin. Multi-phase fluid mechanics theory and application [M]. Beijing: science press, 2008.

[10]Han Zhanzhong, Wang Jing, Lan Xiaoping. The simulation and application of fluid engineering 
[M]. Beijing: Beijing institute of technology press, 2004.

[11]Jia Lan, Song Ziling, Zhao Guang. Numerical simulation of dust particle diffusion elevation movement during a process of large height difference chut [J]. Journal of environmental engineering, 2016, 10 (3) : 1406-1411.

[12]Gu Zhaolin.Wind dust: near-stratospheric turbulence and gas-solid two-phase flow [M]. Science Press, 2010.

[13]LIAO Xianxin,Jiang Zhongan, Niu Wei, et al. Numerical simulation of blasting dust migration with the use of Fluent in stope [J]. Journal of safety and environment, 2012, 12 (6): 43-46. 